\title{
REAL-TIME REAL ECONOMIC ACTIVITY: \\ EXITING THE GREAT RECESSION AND ENTERING THE PANDEMIC RECESSION
}

\author{
Francis X. Diebold \\ Working Paper 27482 \\ http://www.nber.org/papers/w27482 \\ NATIONAL BUREAU OF ECONOMIC RESEARCH \\ 1050 Massachusetts Avenue \\ Cambridge, MA 02138 \\ July 2020
}

For helpful discussion I thank Boragan Aruoba, Glenn Rudebusch, Chiara Scotti, Minchul Shin, Keith Sill, and Tom Stark. For outstanding research assistance and related discussion I thank Philippe Goulet Coulombe, Tony Liu, and Boyan Zhang. The usual disclaimer applies. The views expressed herein are those of the author and do not necessarily reflect the views of the National Bureau of Economic Research.

NBER working papers are circulated for discussion and comment purposes. They have not been peer-reviewed or been subject to the review by the NBER Board of Directors that accompanies official NBER publications.

(C) 2020 by Francis X. Diebold. All rights reserved. Short sections of text, not to exceed two paragraphs, may be quoted without explicit permission provided that full credit, including ( $)$ notice, is given to the source. 
Real-Time Real Economic Activity: Exiting the Great Recession and Entering the Pandemic Recession Francis X. Diebold

NBER Working Paper No. 27482

July 2020

JEL No. E32

\begin{abstract}
We study the real-time signals provided by the Aruoba-Diebold-Scotti Index of Business conditions (ADS) for tracking economic activity at high frequency. We start with exit from the Great Recession, comparing the evolution of real-time vintage beliefs to a "final" late-vintage chronology. We then consider entry into the Pandemic Recession, again tracking the evolution of real-time vintage beliefs. ADS swings widely as its underlying economic indicators swing widely, but the emerging ADS path as of this writing (late June) indicates a return to growth in May. The trajectory of the nascent recovery, however, is highly uncertain (particularly as COVID-19 spreads in the South and West) and could be revised or eliminated as new data arrive.
\end{abstract}

Francis X. Diebold

Department of Economics

University of Pennsylvania

133 South 36th Street

Philadelphia, PA 19104-6297

and NBER

fdiebold@ sas.upenn.edu 


\section{Introduction}

Accurate assessment of of current real economic activity ("business conditions") is key for successful decision making in business, finance, and policy. It is difficult, however, to track business conditions in real time, both because no single observed economic indicator is "business conditions", and because different indicators are available at different observational frequencies, and with different release delays. Nevertheless there exists the tantalizing possibility of accurate real-time business conditions assessment ("nowcasting"), and recent decades have witnessed great interest in nowcasting methods and applications (e.g., BanBura et al. (2011)).

The workhorse nowcasting approaches involve dynamic factor models, which relate a set of observed real activity indicators to a single underlying latent real activity factor. Both "small data" approaches (e.g., based on 5 indicators) and "Big Data" approaches (e.g., based on 500 indicators) are available. Small data approaches came first, and they typically involve maximum likelihood estimation (e.g., Stock and Watson (1989)). Subsequent Big Data approaches, in contrast, typically involve two-step estimation based on a first-step extraction of principal components (e.g., Stock and Watson (2002), McCracken and Ng (2016)).

Both introspection and experience reveal that Big Data nowcasting approaches are not necessarily better. First, they are more tedious to manage, and less transparent. Second, they may not deliver much improvement in factor extraction accuracy, which increases and stabilizes quickly as the number of indicators increases (Doz et al., 2012). Third, casual inclusion of many indicators can be problematic because a poorly-balanced set of indicators can create distortions in the extracted factor (Boivin and $\mathrm{Ng}, 2006$ ), whereas small data approaches promote and facilitate hard thinking about a well-balanced set of indicators (Bai and $\operatorname{Ng}(2008))$.

Against this background, in this paper we assess the performance of a leading small-data nowcast, the Aruoba-Diebold-Scotti (ADS) Index of Business Conditions (Aruoba et al., 2009). ADS is designed to track real business conditions at high frequency, and it has been maintained and released in real time by the Federal Reserve Bank of Philadelphia continuously since 2008. ${ }^{1}$ Its modeling style and underlying economic indicators build on classic

\footnotetext{
${ }^{1}$ The production version used by FRB Philadelphia differs in some ways (e.g., included indicators and treatment of trend) from the prototypes provided by Aruoba et al. (2009) and Aruoba and Diebold (2010), which themselves differ slightly. All discussion in this paper refers to the FRB Philadelphia version. All materials, including the full set of vintage nowcasts, are available at https://www.philadelphiafed.org/ research-and-data/real-time-center/business-conditions-index.
} 
early work in the tradition of Burns and Mitchell (1946), Sargent and Sims (1977), and Stock and Watson (1989). The underlying indicators span high- and low-frequency information on real economic flows: weekly initial jobless claims; monthly payroll employment growth, industrial production growth, personal income less transfer payments growth, manufacturing and trade sales growth; and quarterly real GDP growth.

Crucially, we assess ADS performance using only information actually available in real time. This is required for truly credible real-time evaluation, and it can only be achieved by using nowcasts produced and permanently recorded in real time, which is very different from simply removing final-revised data and inserting vintage data into an otherwise ex post analysis. Unfortunately, such evaluations are rare, because there simply are not many instances of long series of nowcasts produced and recorded in real time. ADS, however, has been produced and recorded in real time roughly twice weekly since late 2008, so we can provide real-time performance assessments both exiting the Great Recession and entering the Pandemic Recession.

We proceed as follows. In section 2 we provide background on aspects of ADS construction, updating, ex post characteristics, and performance evaluation. In section 3 we evaluate ADS performance exiting the Great Recession. In section 4 we evaluate ADS performance entering the Pandemic Recession. We conclude in section 5.

\section{ADS Construction, Characteristics, and Assessment}

Here we provide background on index construction (section 2.1), ex post historical characteristics (section 2.2), and general issues of relevance to assessing ex ante nowcasting performance (section 2.3).

\subsection{Construction and Updating}

ADS is a dynamic factor model with multiple indicators and a single latent real activity factor. The ADS index is an estimate of that latent real activity factor. Importantly, the model is specified such that the real activity factor tracks the de-meaned growth rate of real activity. Hence zero ADS does not indicate zero growth; rather, zero ADS indicates "normal" growth. Progressively more negative or positive values indicate progressively worseor better-than-average real growth, respectively.

ADS is specified at daily frequency, allowing as necessary for missing data for the less- 
Figure 1: ADS Index: Ex Post Path 03/01/1960 - 12/31/2013 (Vintage 6/26/2020)

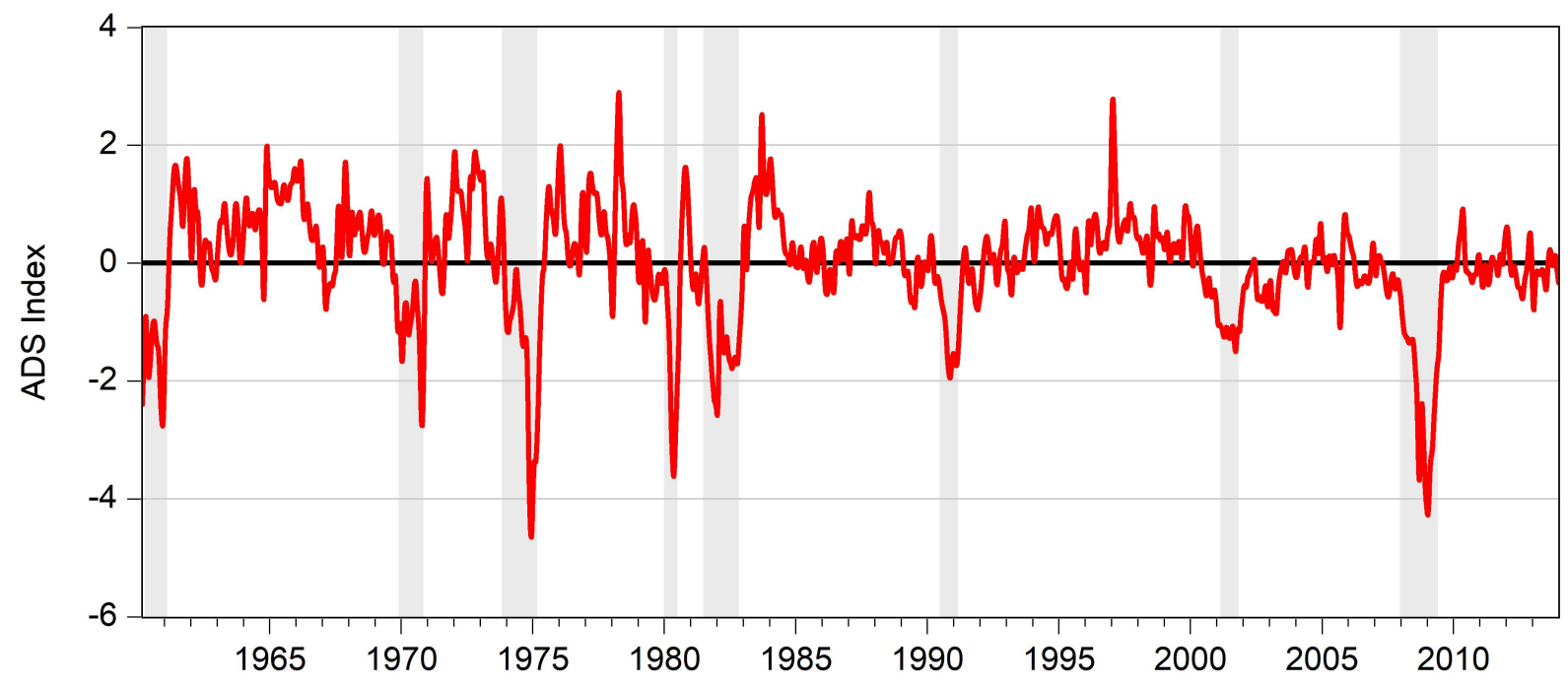

Notes: The shaded regions are NBER-designated recessions.

frequently observed variables. ${ }^{2}$ Importantly, despite complications from missing data, timevarying system matrices, aggregation across frequencies, etc., the Kalman filter and associated Gaussian pseudo likelihood evaluation via prediction-error decomposition remain valid, subject to some well-known modifications. ${ }^{3}$ Model estimation is therefore straightforward, after which the Kalman smoother produces an optimal extraction of the underlying real activity factor. That is, the Kalman smoother produces the ADS index: The extracted sequence at any time $t^{*}$ is the vintage- $t^{*}$ ADS sequence, $\left\{A D S_{1}, A D S_{2}, \ldots A D S_{t^{*}}\right\}$.

The first ADS vintage was released 12/5/2008, covering 3/1/1960 through 11/30/2008. Since then, ADS has been continuously updated whenever new data are released. The Kalman smoother is re-run, generally within two hours of the release, and the newlyextracted index is re-written to the web from 3/1/1960 to "the present". ADS has been updated approximately eight times per month on average since inception. 


\subsection{Ex Post Characteristics}

In Figure 1 we show the ADS index from 03/01/1960 through 12/31/2006, as assessed in the $6 / 26 / 2020$ vintage. The sample range is well before the vintage pull date, so the chronology displayed is (intentionally) ex post. We do this because it is instructive to examine the ex post chronology before passing to real time assessment, which can only be done after ADS went live in late $2008 .^{4}$

Several features are noteworthy. For example, the ADS chronology coheres strongly with the NBER chronology, plunging during NBER recessions. In addition, several often-discussed features of the business-cycle are evident in ADS, such as the pronounced moderation in volatility during the Greenspan era.

The ADS value added relative to the NBER chronology stems from the facts that (1) it is a cardinal measure, allowing one to assess not only recession durations, but also depths and patterns (see Table 1), and (2) its updates arrive in timely fashion, whereas NBER recession start and end dates are typically not announced until long after the fact (again see Table 1). Of course, if ADS is to be a useful guide for business and policy decisions, its frequently-arriving updates must provide reliable signals in real time, not just ex post as in Figure 1. We now turn to that issue.

\subsection{Performance Assessment}

Truly credible nowcasting performance assessment requires using vintage information, which emerges as the limit of a sequence of progressively more realistic and credible nowcast/forecast evaluation approaches: ${ }^{5}$

1. Use full-sample estimation, and use final revised data

2. Use expanding-sample estimation, and use final revised data

3. Use expanding-sample estimation, and use vintage data ("Pseudo Real Time")

\footnotetext{
${ }^{2}$ The model must be specified at daily frequency, despite the fact that the highest-frequency indicator is is weekly initial jobless claims, to account for the varying number of days/weeks per month, which also produces time-varying system parameter matrices.

${ }^{3}$ See, for example, Durbin and Koopman (2001) on missing data, and Harvey (1991) on aggregation of flow variables.

${ }^{4}$ The sample period intentionally excludes the Pandemic Recession, which we will subsequently examine in detail.

${ }^{5}$ Note that nowcasts are effectively just $h$-step-ahead forecasts with horizon $h=0$.
} 
Table 1: NBER Recessions

\begin{tabular}{|c|c|c|c|c|}
\hline \multicolumn{2}{|c|}{ Recession Dates } & \multicolumn{3}{|c|}{ Recession Characteristics } \\
\hline Peak Month & Trough Month & Duration & Depth & Severity \\
\hline April 1960 & February 1961 & 10 & 2.7 & 27.0 \\
\hline December 1969 & November 1970 & 11 & 2.8 & 30.8 \\
\hline November 1973 & March 1975 & 16 & 4.7 & 75.2 \\
\hline January 1980 (6/3/1980) & July 1980 (7/8/1981) & 6 & 3.6 & 21.6 \\
\hline July $1981(1 / 6 / 1982)$ & November $1982(7 / 8 / 1983)$ & 16 & 2.9 & 46.4 \\
\hline July $1990(4 / 25 / 1991)$ & March 1991 (12/22/1992) & 8 & 1.7 & 13.6 \\
\hline March $2001(11 / 26 / 2001)$ & November $2001(7 / 17 / 2003)$ & 8 & 1.5 & 12.0 \\
\hline December 2007 (12/1/2008) & June 2009 (9/20/2010) & 18 & 4.3 & 77.4 \\
\hline February $2020(6 / 6 / 2020)$ & $?$ & $?$ & $?$ & $?$ \\
\hline
\end{tabular}

Notes: Recession dates and durations in months are from the NBER chronology; see https://www.nber . org/cycles.html. When available, the announcement dates appear in parentheses. The NBER trough month for the Pandemic Recession has not yet been announced. Recession depth is the minimum absolute daily ADS value during the recession; more precisely, the depth $D$ of recession $R$ is $D=\left|\min _{i}\left(A D S_{i}\right)\right|$, $i \in R$, where $i$ denotes days. Recession severity $S$ is the product of depth and duration. Both $D$ and $S$ use a late-vintage ADS chronology and the NBER recession chronology.

4. Use expanding-sample estimation, and use vintage information ("Real Time").

Approaches 1 and 2 are clearly unsatisfactory: Approach 1 uses time periods and data values not available in real time, and approach 2 is an improvement but still uses data not available in real time. Approach 3, involving vintage data, is typically viewed as the gold standard. It is implemented comparatively infrequently, however, due to the tedium involved and the fact that vintage data are often unavailable. ${ }^{6}$ Approach 4 , use of vintage information, limits the information set to that available and actually used in real time, which is more restrictive than merely limiting the data to that available in real time. It is, however, almost never implemented.

To appreciate why fully-credible assessment requires vintage information rather than just vintage data, consider the following:

1. Econometric/statistical theory and experience evolve, prompting changes to the estimation procedure; the frequency and timing of re-estimation and its interaction with

\footnotetext{
${ }^{6}$ The two key sources of U.S. vintage data are the Real-Time Dataset for Macroeconomists at the Federal Reserve Bank of Philadelphia (https://www.philadelphiafed.org/research-and-data/ real-time-center/real-time-data/), and ALFRED at the Federal Reserve Bank of St. Louis (https: //alfred.stlouisfed.org/).
} 
benchmark revisions; the estimation sample period; allowance for parameter variation and breaks; the treatment of outliers; the strength of regularization employed; the predictive loss function employed; etc.

2. Economic theory and empirical economic experience evolve. Over time this may prompt, for example, the removal or re-weighting of some component nowcast indicators and/or addition of others (e.g., Diebold and Rudebusch (1991)), as well as deeper changes in the nowcasting model.

3. Exact times and reliability of nowcast/forecast calculation and release may differ due to technological problems; outright mistakes in nowcast/forecast construction; evolving or changing software algorithms and associated bugs; parallel problems at the agencies responsible for the underlying data and decisions regarding how to deal with them in forecast/nowcast construction; etc.

For these and other reasons, just as truly credible evaluation requires refraining from endowing agents with better data than were actually available in real time, so too does it require refraining from endowing them with better economic or statistical models and related tools than were actually available in real time, better judgment and decision-making abilities/choices than were actually manifest in real time, etc.

The upshot is clear: Truly credible real-time evaluation - that is, evaluation using vintage information rather than just vintage data - can only be obtained by using nowcasts produced and permanently recorded in real time. ADS has been produced and recorded in real time since late 2008, so as of this writing we can study two key episodes: exit from the Great Recession and entry into the Pandemic Recession. We now proceed to do so.

\section{Exiting the Great Recession}

We refer to a real-time ADS extraction as a path, and a graph of a sequence of paths as a path plot. ${ }^{7}$ By following the path plot rightward, moving through time, we track the evolution of ADS beliefs about the chronology of business conditions. We cannot examine real-time ADS performance when entering the Great Recession, because ADS did not start until December 2008, well after the great recession began. But we can examine real-time ADS performance when exiting the great recession.

\footnotetext{
${ }^{7}$ Sometimes we call path plots "tentacle plots", because the paths resemble the tentacles of a jellyfish.
} 
Figure 2: Exiting the Great Recession: Five Quarterly Real-Time ADS Paths
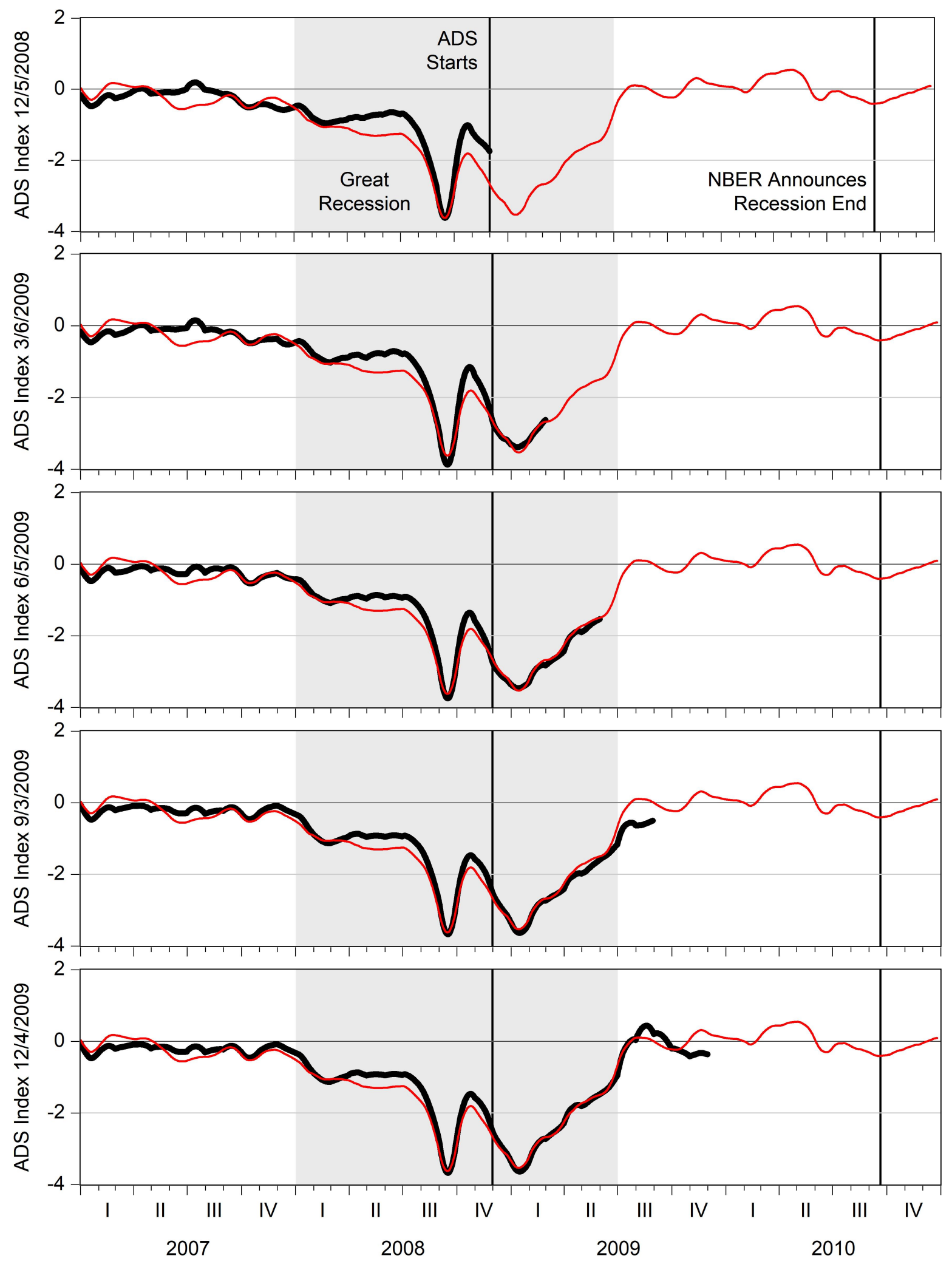

Notes: We show five quarterly real-time ADS paths in black. From top to bottom they are $12 / 5 / 2008,3 / 6 / 2009,6 / 5 / 2009,9 / 3 / 2009,12 / 4 / 2009$. For comparison we show a latevintage ADS path (December 2010) in red. 
In Figure 2 we show five paths in black, from ADS inception through the end of the Great Recession, at quarterly intervals. For comparison we also show a late-vintage path in red. One can think of the late-vintage path as "truth", or at least a good assessment of truth based on late-vintage data. It is revealing to compare the real-time paths to the ex post path.

In the top panel of Figure 2 we show the first ADS path, 12/5/2008. ADS shows a very deep recession, almost the deepest on record since 1960, bottoming out in 2008Q3, with movement toward recovery in late Q3 and early Q4, even if it had stalled a bit by early December. As it turned out, however, the Great Recession subsequently featured a growth rate "double dip". The 12/5/2008 ADS path ends just after the first dip, which involved a sharp drop in September 2008 and an equally sharp rebound. ${ }^{8}$ At the time it was easy to read the cards as saying that the recession was ending, and ADS was a bit too optimistic, moving upward toward recovery.

Now consider the remaining panels of Figure 2. In the second panel we show the next, and contrasting, 3/6/2008 ADS path. In the interim ADS has quickly learned the situation, the double dip in particular, and is very much on track, capturing the second dip in January 2009. ADS continues to climb steadily through the third and fourth panels $(6 / 5 / 2009$ and $9 / 3 / 3009$, respectively), and by the time of the bottom panel $(12 / 4 / 2009)$ it is clear that the Great Recession ended in June or July, with ADS basically fluctuating around 0 after that. (Recall that $\mathrm{ADS}=0$ means average growth, not zero growth.)

All told, the five quarterly real-time ADS paths generally match the ex post path closely, and they correctly identify the recession's end, well before the end of 2009 and indeed roughly 1.5 years before the official NBER announcement in September 2010.

To emphasize ADS timeliness, we plot the late vintage ADS in Figure 2 all the way through 2010, which allows inclusion of the NBER's end-of-recession announcement on 9/20/2010, long after the fact and not helpful for real-time decision making. ${ }^{9}$ ADS fills the gap left by the late-arriving NBER chronology, and it also provides a numerical measure that allows one to track the recession's pattern, depth, overall severity, etc., in addition to

\footnotetext{
${ }^{8}$ In particular, according to the Federal Reserve's G.17 Industrial Production (IP) release of October 16, 2008, September IP was severely affected by a highly-unusual and largely exogenous "triple shock" (Hurricanes Gustav and Ike, and a strike at a major aircraft manufacturer), which caused an annualized September IP drop of nearly fifty percent. A similar pattern exists for Manufacturing and Trade Sales (MTS). IP and MTS also rebounded unusually sharply in October - indeed IP appears to "overshoot" presumably in an attempt by manufacturers to make up for September's loss.

${ }^{9}$ Of course the NBER is not seeking to be helpful for real-time decision making; rather, they seek to meticulously construct the U.S. business cycle chronology of record, quite reasonably using all relevant information - even very late-arriving information.
} 
Figure 3: Exiting the Great Recession: Real-Time ADS Path Plot

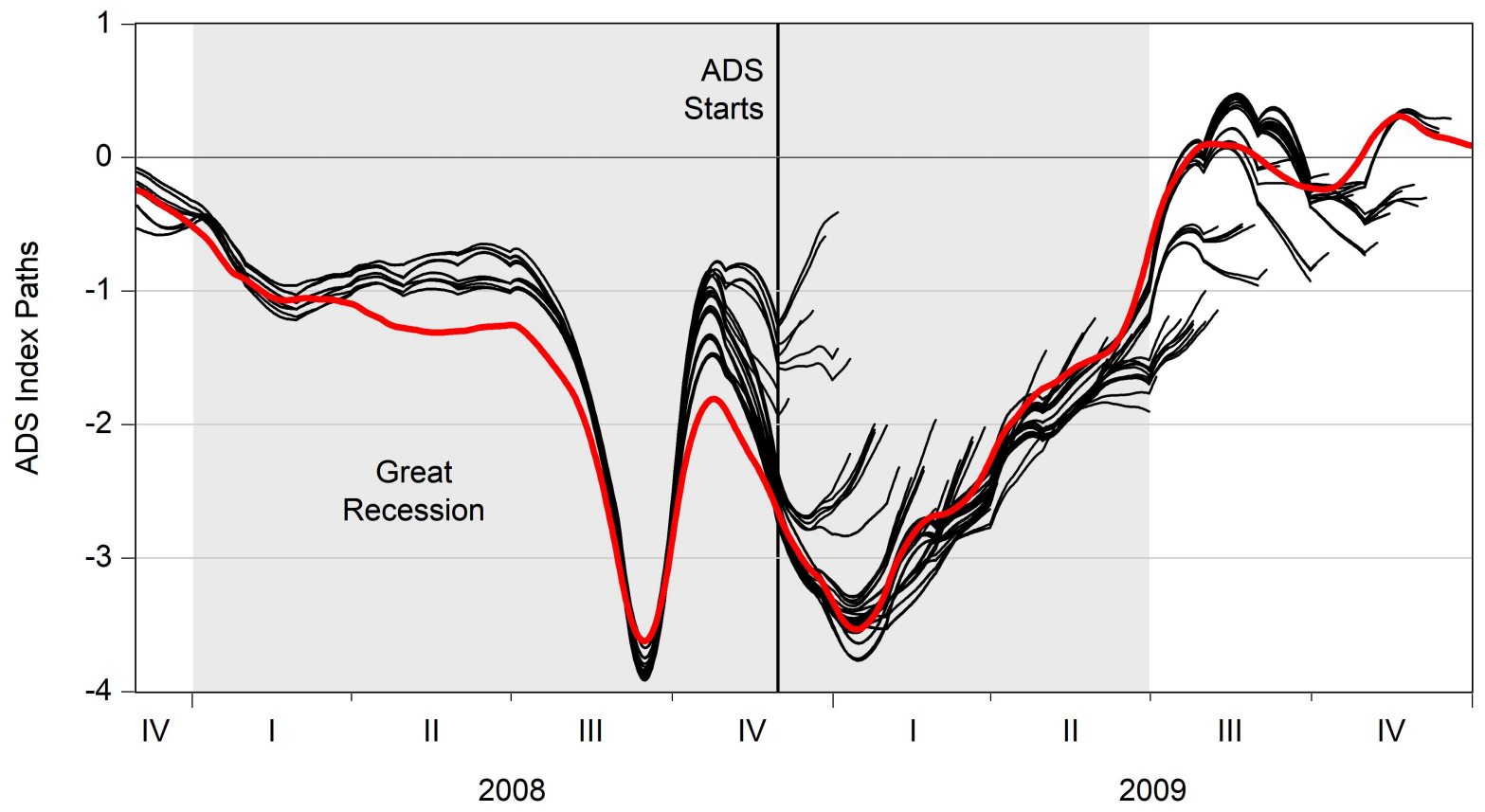

Notes: We show all 2008-2009 ADS paths since the first on 12/5/2008. We show real-time ADS paths in black, and a comparison late-vintage ADS path (December 2010) in red.

duration. For example and as recorded in Table 1, ADS identifies the Great Recession as the worst since 1960 and through 2010, with longest duration and second-greatest depth, resulting in the greatest overall severity (duration times depth).

In Figure 3 we show the complete path plot (the set of all real-time paths). Of course there are errors positive and negative as the recession evolves, but overall ADS performs well, sending a reliable and valuable signal for navigating the path out of recession. We show the corresponding "dot plot" in Figure 4; each dot is the last observation of its corresponding path in Figure 3. The dots are real-time smoothed values. ${ }^{10}$ The black-dot sequence of real-time smooths is naturally less variable than the later-vintage (December 2010) smooth shown in red, because the latter has more information on which to condition, and therefore captures more variation.

\footnotetext{
${ }^{10}$ They are also filtered, because smoothed and filtered values coincide for the last observation in a sample.
} 
Figure 4: Exiting the Great Recession: Real-Time ADS Dot Plot

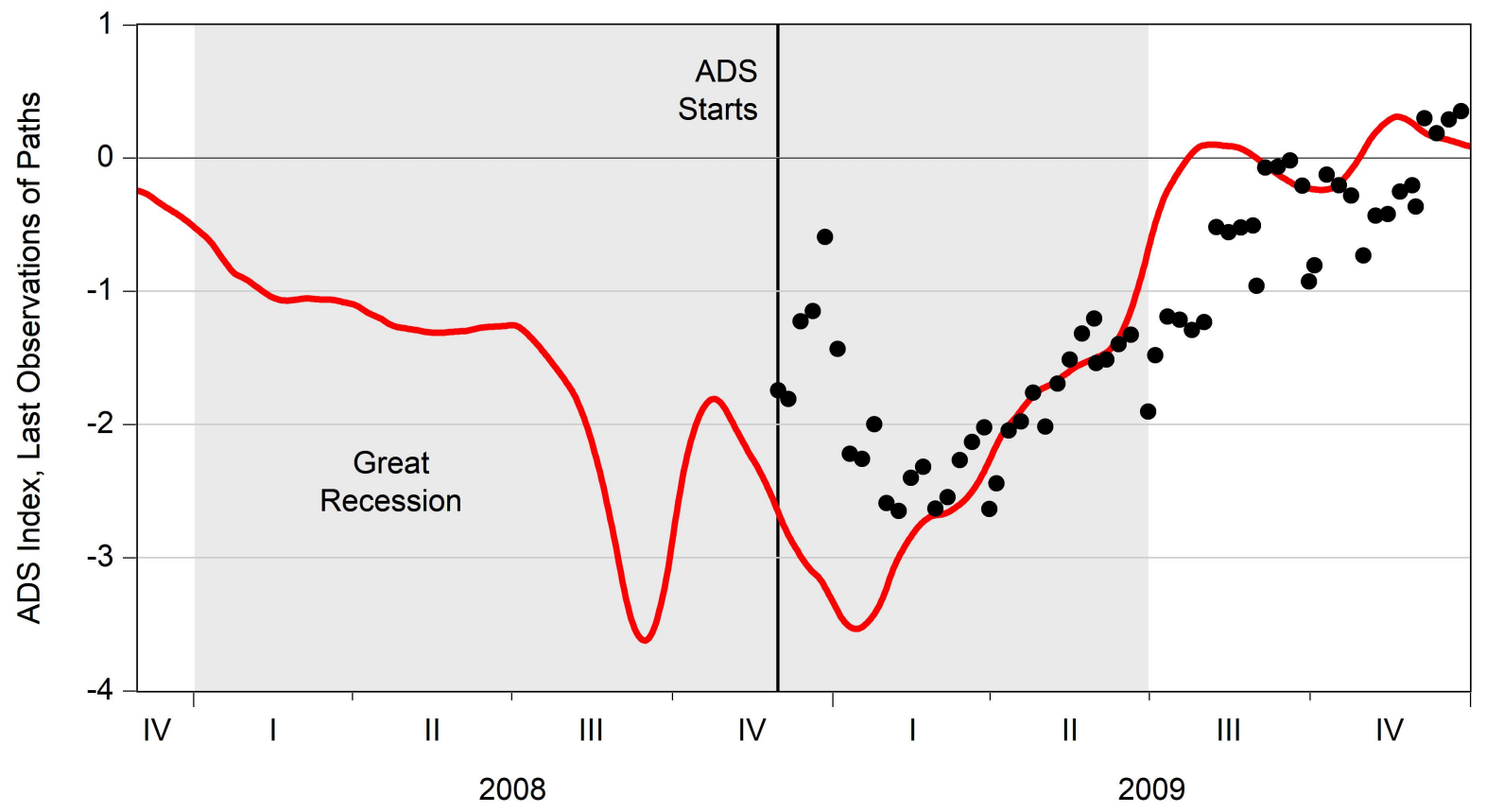

Notes: We show the final values of each 2008-2009 ADS path in black, with a comparison late-vintage ADS path (December 2010) superimposed in red.

\section{Entering the Pandemic Recession}

We focus in this section on the Pandemic Recession that started in March 2020. It is instructive to begin by comparing it to the Great Recession of 2007-2009. To that end we show the ADS path in Figure 5, from late 2007 through the date of this writing. The so-called "Great Recession" appears minor by comparison.

\subsection{A Detailed Look at the Latest Vintage Path}

\subsubsection{Depth}

Figure 5 reveals the jaw-dropping ADS drop in the Pandemic Recession, more than five times that of any other recession since 1960. The ADS drop is entirely appropriate, due to similarly jaw-dropping and historically unprecedented movements in its underlying indicators. ${ }^{11}$

We can interpret ADS depth by calibrating the sum of the worst two quarters of GDP

\footnotetext{
${ }^{11}$ See Appendices A and B for chronologies of data releases and ADS movements, respectively.
} 
Figure 5: ADS Index: Ex Post Path 12/1/2007 - 6/26/2020 (Vintage 6/26/2020)

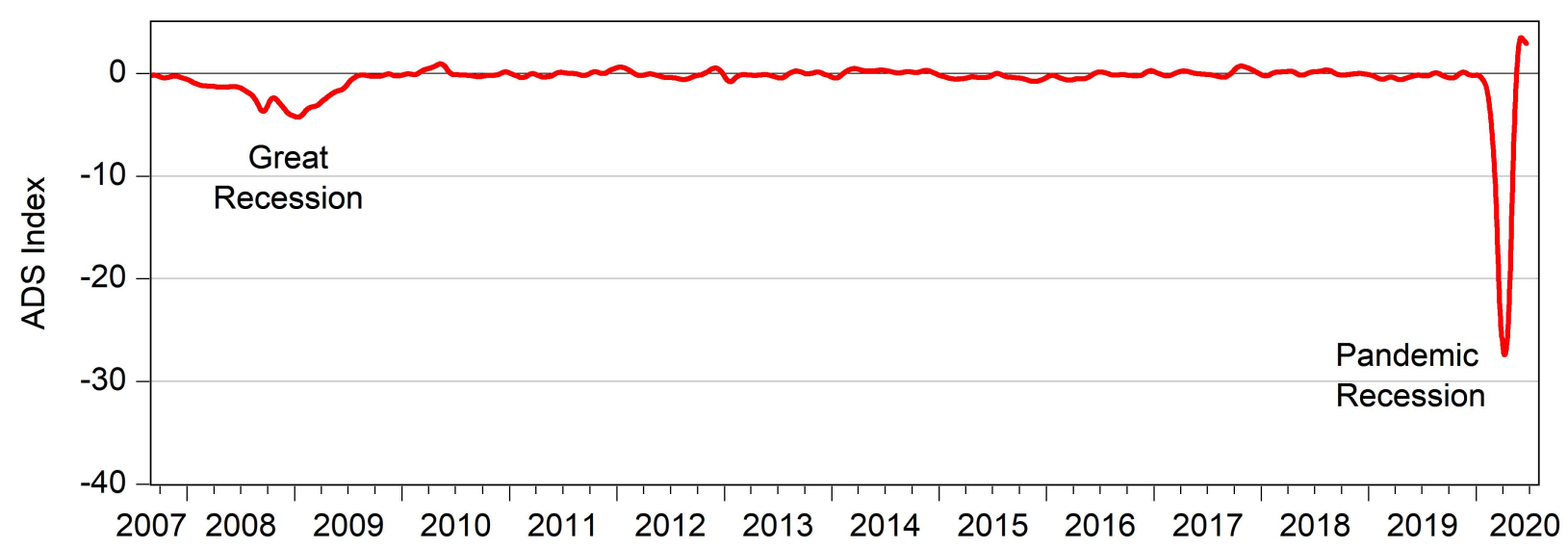

growth in a recession to the worst ADS. Use of two-quarter GDP, and not requiring that the two quarters be contiguous, is helpful because recession troughs may straddle quarterly boundaries, and moreover because some recessions may have "double-dips". In Figure 6 we show a scatterplot of the sum of worst two quarters of GDP growth vs. worst ADS. The fitted regression line is

$$
\widehat{G D P_{R}}=-.33+.54 A D S_{R},
$$

where $G D P_{R}$ is the sum of the worst two quarters of GDP growth in recession $R$, and $A D S_{R}$ is the worst $A D S$ in recession $R$. The slope is quite precisely estimated (s.e. =.18), and $R^{2}=.61$. As a quick approximation we can use $\widehat{G D P_{R}}=.5 A D S_{R}$. Figure 5 shows an ADS minimum of roughly -25 , corresponding (via equation (1)) to a two-quarter annualized GDP growth of roughly $-12 \%$, or roughly $-6 \%$ for each of two quarters.

\subsubsection{Duration}

As of this writing, the official trough month for the Pandemic Recession has not been announced. It could be as early as May 2020, in which case the Pandemic Recession would be the shortest in history. (A May trough turns out to be likely, if highly uncertain, conditional on information available through June, as we will soon discuss.) The trough could of course also be later, perhaps with additional dips due to continued spread and potential resurgence of COVID-19. 
Figure 6: Worst Two GDP Quarters vs. Worst ADS

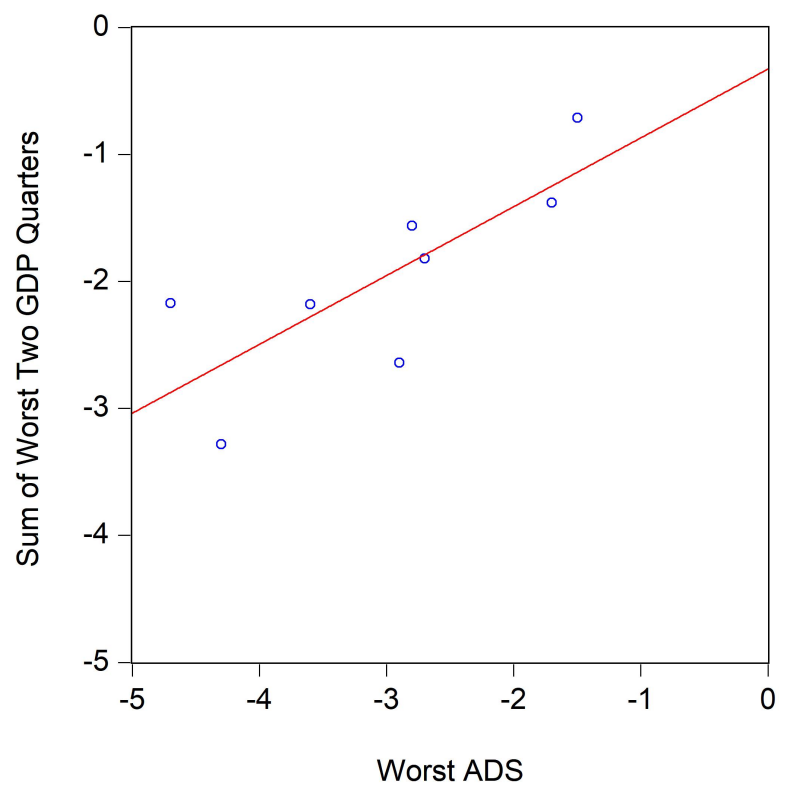

Notes: We show the sum of the worst two quarters of GDP vs. the worst ADS value, for each recession except the Pandemic Recession (both the GDP drop and the ADS drop are as-yet unknown for the Pandemic Recession), together with the fitted regression line.

\subsubsection{General Pattern}

In Figure 7 we show the latest-vintage Pandemic Recession path. The overall extracted path is smooth and convex, with a minimum in early April, and a return to average growth by mid-May. We emphasize again, however, that ADS measures real activity growth, not level. Hence positive ADS does not necessarily mean "good times"; rather, it means "good growth", which may be from a very bad initial condition. That was evidently the situation in late May, as the battered U.S. economy evidently resumed growth.

\subsection{Real-Time Vintages}

\subsubsection{Five Snapshots}

In Figure 8 we show several end-of-month paths in black, starting with February 2020. For comparison, in each panel we also show the latest-vintage path in red. One should not think of the later-vintage path as "truth", because it may be revised as new data arrive. Ideally we would like to use a vintage from a year or two after the recession's end, as with our use of the 
Figure 7: ADS Index: Ex Post Path 1/1/2020 - 6/26/2020 (Vintage 6/26/2020)

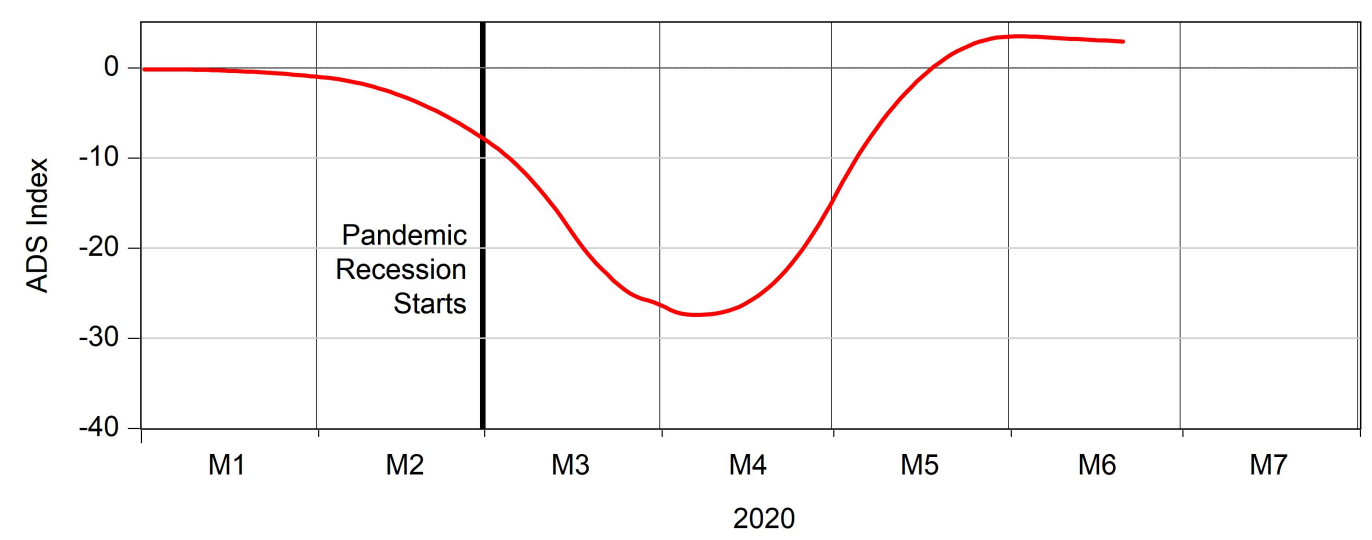

December 2010 vintage as a reference path when assessing ADS during the Great Recession in section 4, but we do not have that luxury at present. Meanwhile it is still informative to compare the last-available path to earlier paths. Moving through the five panels of Figure 8:

1. In the top panel we show the $2 / 28 / 2020$ path. ADS has not moved.

2. In the second panel we show the $3 / 27 / 2020$ path, which looks very different. ADS has become acutely aware of the disastrous situation; indeed most of the $3 / 27$ path is well below the previous all-time (post-1960) ADS low during the 1970s oil-shock recession. ${ }^{12}$

3. In the third panel we show the 4/30/2020 path. The April initial claims news is bad, but less bad than March, which is good, and ADS shows a minimum in late March followed by a rise toward normalcy by the end of April.

4. In the fourth panel we show the $5 / 29 / 2020$ path. The May news is very bad, dominated by the shockingly bad May 8 payroll employment number (for April), and the late-May path is massively down-shifted relative to the late-April path. The new minimum is in mid-April rather than late March, and the 5/29 ADS value is thoroughly dismal, nowhere near normalcy.

5. In the fifth panel we show the 6/26/2020 path. Thanks to the strong May payroll employment number (released June 5), ADS moved into normal territory, and stayed

\footnotetext{
${ }^{12}$ It is also apparent that the Kalman smoother may be smoothing "too much", producing low ADS values well before mid-March, going back into February and even January. Its smoothing is optimal relative to the patterns in historical data, but the March initial jobless claims movements were unprecedentedly sharp.
} 
Figure 8: Entering the Pandemic Recession: Monthly Real-Time ADS Paths
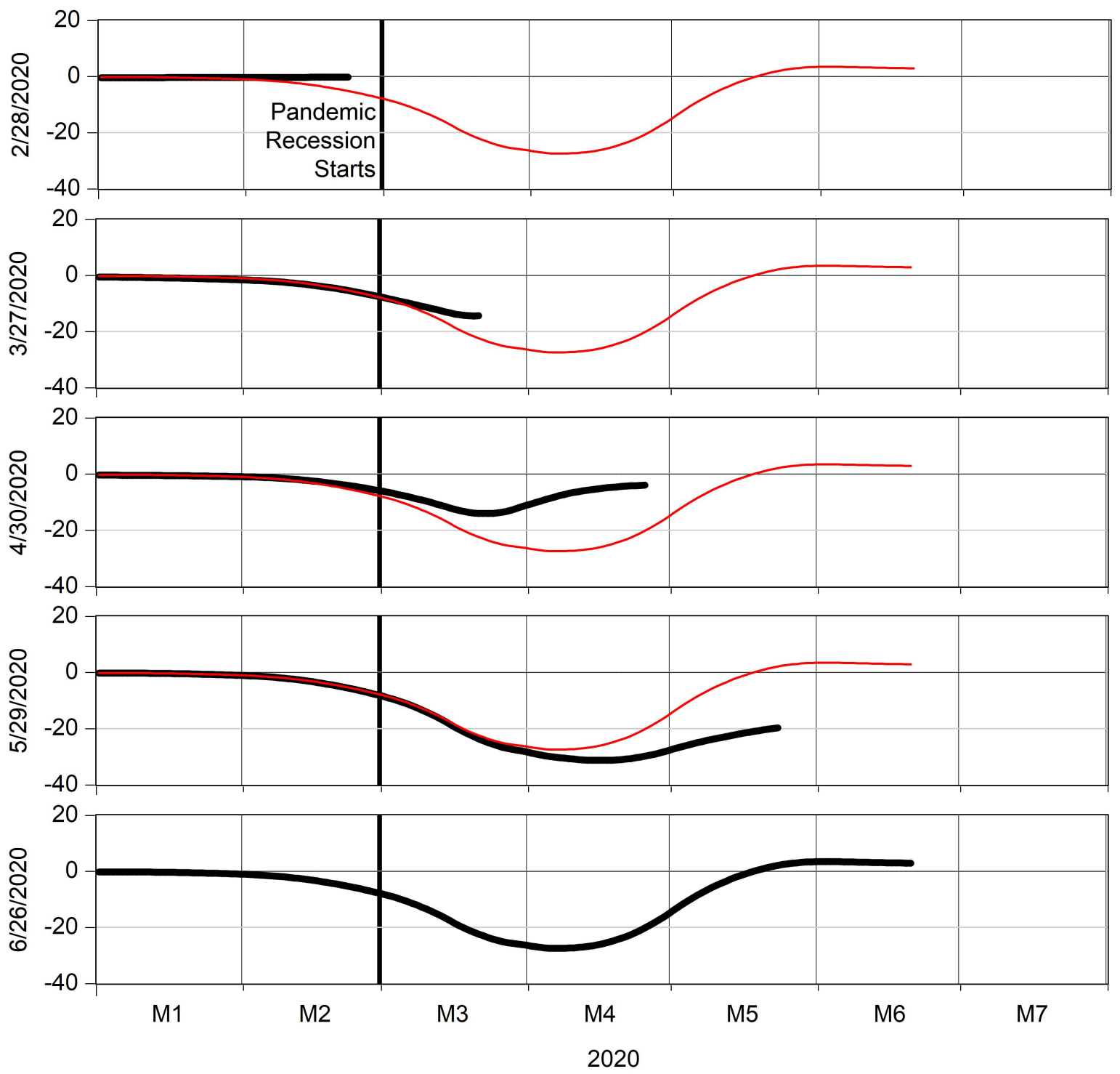

Notes: We show five monthly real-time ADS paths in black. From top to bottom they are $2 / 28 / 2020,3 / 27 / 2020,4 / 30 / 2020,5 / 29 / 2020$, and 6/26/2020. For comparison we show the $6 / 26 / 2020$ path in red in all panels. (In the bottom panel, we show only black, since black and red are identical.) 
Figure 9: Entering the Pandemic Recession: Real Time ADS Path Plot

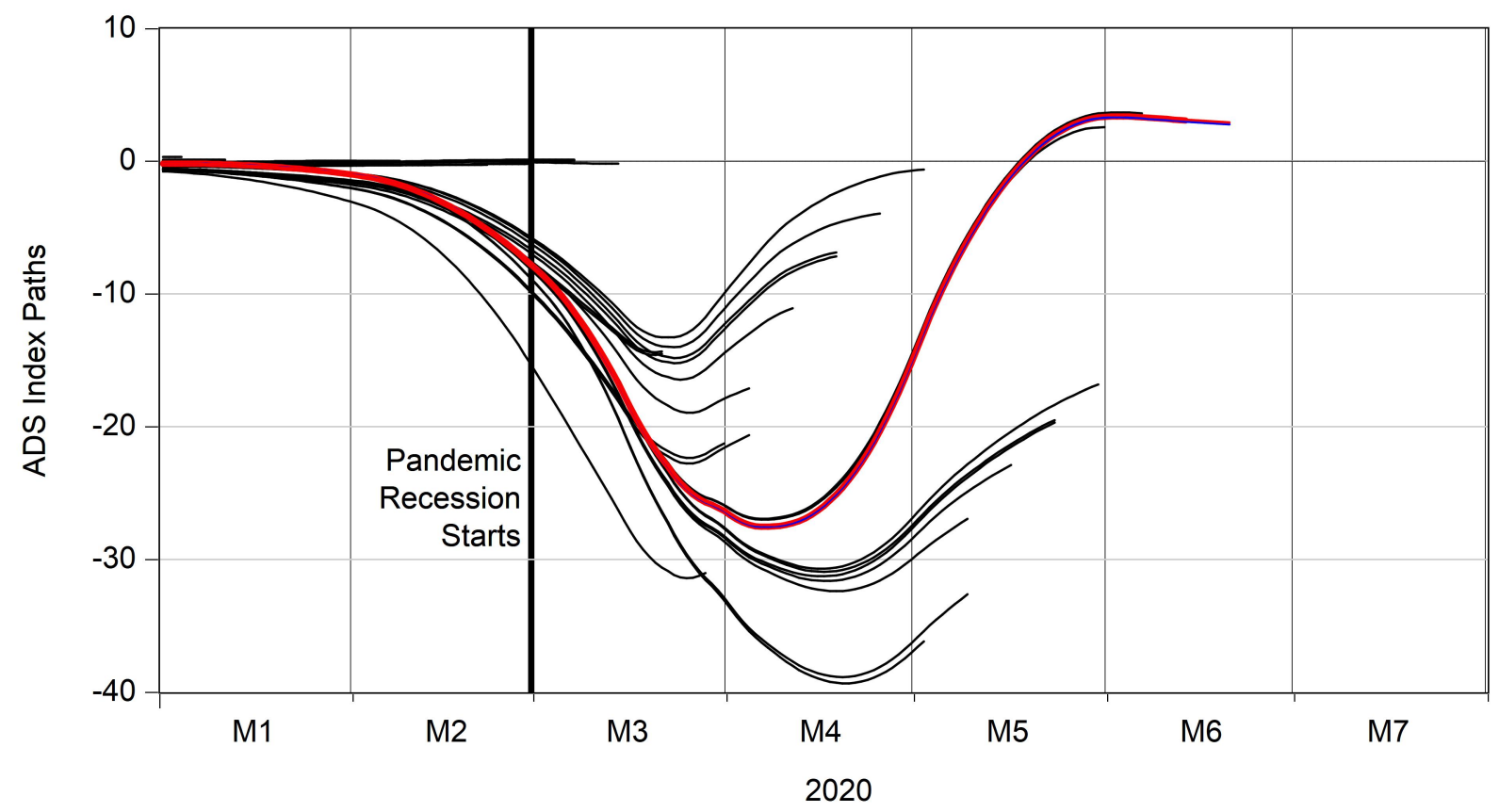

Notes: We show all real-time 2020 ADS paths in black, through 6/26/2020. For comparison we show the complete final-vintage path $(6 / 26 / 2020)$ in red.

there. There is clear (albeit highly-tentative evidence for a Pandemic Recession trough in mid-May, when ADS hits 0.)

\subsubsection{The Full Path Plot}

In Figure 9 we show the complete path plot during the Pandemic Recession through 6/26/2020, with the final path in red for comparison. In Appendix B we provide a corresponding annotated path chronology.

There are wide real-time divergences between individual early paths and the latestvintage red path. There are interesting patterns, however, with several real-time "meta paths" evident:

1. The first extends through the 3/19/2020 ADS announcement. ADS does not move. Initial claims rise from $0.2 \mathrm{~m}$ to $0.3 \mathrm{~m}$, a large move by historical standards, confirming what everyone already knew: the pandemic would have important real economic 
Figure 10: Exiting the Pandemic Recession: Real-Time ADS Dot Plot

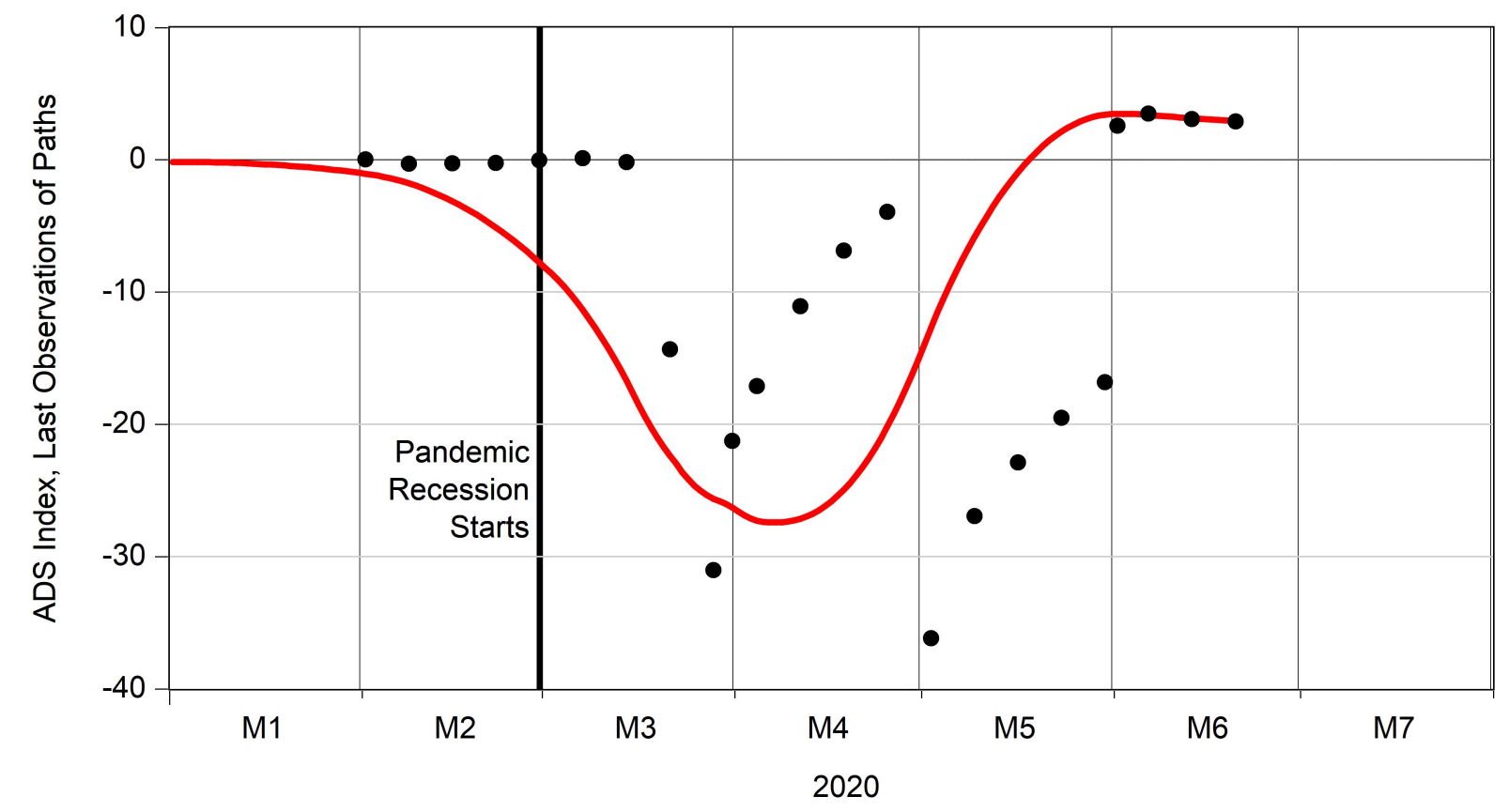

Notes: We show the final values of all real-times 2020 ADS paths in black. For comparison we show the complete final-vintage path $(6 / 26 / 2020)$ in red.

consequences, but the Kalman smoother optimally but erroneously ascribes it to measurement error.

2. The second meta-path begins with the $3 / 26 / 2020$ and 4/2/2020 initial claims explosions. ADS plunges, but then recovers steadily despite a steady stream of bad news (it is bad, but getting less bad), almost back to 0 by the 5/7/2020 initial claims announcement.

3. The third meta-path begins with the horrific 5/8/2020 April payroll employment release, with ADS again plunging. It then again begins mean reverting, and does so completely when the strong May payroll employment number is released on 6/5/2020.

In Figure 10 we show the corresponding dot plot, with the 6/26/2020 path again superimposed. The dot plot is highly volatile and emphasizes the various meta-paths. 


\section{Concluding Remarks}

Our approach was part methodological and part substantive. On the methodological side, we clarified the meaning of truly honest real-time nowcast/forecast evaluation and illustrated it using the ADS Business Conditions Index, which has now been in operation over a long span that includes emergence from the Great Recession and entry into the Pandemic Recession. On the substantive side, we explored how views formed using best-practice nowcasts evolved when exiting the Great Recession, which is now a settled historical episode, and when entering the Pandemic Recession, which continues to swirl around us.

We started with exit from the Great Recession, comparing the evolution of real-time vintage beliefs to a "final" late-vintage chronology. We then moved to entry into the Pandemic Recession, which arrived abruptly and was caused by non-economic factors, again tracking the evolution of real-time vintage beliefs. During March-June 2020, ADS swung widely as its underlying components swung widely, but as of the date of this writing (late June 2020) ADS indicates a very deep but also very short recession, with a business cycle trough in May 2020. The trajectory of the nascent recovery, however, is highly uncertain - particularly as COVID-19 spreads in the South and West - and could be revised or eliminated as new data arrive.

Models generally cannot be expected to perform well in out-of-sample environments wildly different from the training environment. This is all the more so for linear models like ADS, which in reality are just locally-linear approximations. From this vantage point the credible out-of-sample performance of ADS is rather remarkable. Nevertheless, nonlinear/non-Gaussian ADS extensions could perhaps be usefully entertained, for example using the framework of Gunsilius and Schennach (2019). 


\section{Appendices}

\section{A Pandemic Recession Entry: Data Releases}

03/17/2020, Industrial Production (for February 2020), data 09:15, ADS 10:45

03/19/2020, Initial Jobless Claims (for week ending 03/14/2020), data 08:30, ADS 10:00

03/26/2020, Initial Jobless Claims (for week ending 03/21/2020), data 08:30, ADS 10:00

03/26/2020, Real GDP (fourth quarter 2019, third release), data 08:30, ADS 10:00

03/27/2020, Real Manufacturing \& Trade Sales (for January 2020), data 08:30, ADS 10:00

03/27/2020, Real Personal Income Less Transfers (for February 2020), data 08:30, ADS 10:00

04/02/2020, Initial Jobless Claims (for week ending 03/28/2020), data 08:30, ADS 10:00

04/03/2020, Payroll Employment (for March 2020), data 08:30, ADS 10:00

04/09/2020, Initial Jobless Claims (for week ending 04/04/2020), data 08:30, ADS 10:00

04/15/2020, Industrial Production (for March 2020), data 09:15, ADS 10:45

04/16/2020, Initial Jobless Claims (for week ending 04/11/2020), data 08:30, ADS 10:00

04/23/2020, Initial Jobless Claims (for week ending 04/18/2020), data 08:30, ADS 10:00

04/29/2020, Real GDP (first quarter 2020, first release), data 08:30, ADS 10:00

04/30/2020, Initial Jobless Claims (for week ending 04/25/2020), data 08:30, ADS 10:00

04/30/2020, Real Manufacturing \& Trade Sales (for February 2020), data 08:30, ADS 10:00

04/30/2020, Real Personal Income Less Transfers (for March 2020), data 08:30, ADS 10:00

05/07/2020, Initial Jobless Claims (for week ending 05/02/2020), data 08:30, ADS 10:00

05/08/2020, Payroll Employment (for April 2020), data 08:30, ADS 10:00

05/14/2020, Initial Jobless Claims (for week ending 05/09/2020), data 08:30, ADS 10:00

05/15/2020, Industrial Production (for April 2020), data 09:15, ADS 10:45

05/21/2020, Initial Jobless Claims (for week ending 05/16/2020), data 08:30, ADS 10:00

05/28/2020, Initial Jobless Claims (for week ending 05/23/2020), data 08:30, ADS 10:00

05/28/2020, Real GDP (first quarter 2020, second release), data 08:30, ADS 10:00

05/29/2020, Real Manufacturing \& Trade Sales (for March 2020), data 08:30, ADS 10:00

05/29/2020, Real Personal Income Less Transfers (for April 2020), data 08:30, ADS 10:00

06/04/2020, Initial Jobless Claims (for week ending 05/30/2020), data 08:30, ADS 10:00

06/05/2020, Payroll Employment (for May 2020), data 08:30, ADS 10:00

06/11/2020, Initial Jobless Claims (for week ending 06/06/2020), data 08:30, ADS 10:00

06/16/2020, Industrial Production (for May 2020), data 09:15, ADS 10:45

06/18/2020, Initial Jobless Claims (for week ending 06/13/2020), data 08:30, ADS 10:00 
06/25/2020, Initial Jobless Claims (for week ending 06/20/2020), data 08:30, ADS 10:00

06/25/2020, Real GDP (first quarter 2020, third release), data 08:30, ADS 10:00

06/26/2020, Real Manufacturing \& Trade Sales (for April 2020), data 08:30, ADS 10:00

06/26/2020, Real Personal Income Less Transfers (for May 2020), data 08:30, ADS 10:00

\section{B Pandemic Recession Entry: Annotated Chronology}

March 17 (February industrial production). The day of the last ADS update before the March 19 initial claims release. ADS continued its more-or-less random vibration around zero, sending the same signal that it had sent since the end of the Great Recession in 2009: the economy is growing normally. $\mathrm{ADS}=0.1$.

March 19 (initial jobless claims). IJC took a large move upward, confirming what everyone already knew: the pandemic would have important real economic consequences. The Kalman smoother optimally but erroneously ascribed this first-time IJC jump almost entirely to measurement error, and ADS basically did not move. ADS=-0.2.

March 26 (initial jobless claims). IJC spiked in jaw-dropping off-the-chart fashion. Two huge IJC moves in a row are not optimally ascribed to measurement error by the Kalman smoother; rather, they are naturally ascribed to the underlying serially-correlated real activity factor - and ADS drops to approximately - 15 in similarly (and literally) off-the-chart fashion. By way of comparison, the all-time ADS lows since 1960 were in the recessions of 1973-1975 and 2007-2009, in both cases between -4 and -5 . Note that the ADS path now begins its drop earlier in the year, a result of the serial correlation in IJC interacting with the Kalman smoother. It is interesting to speculate as to whether real activity really was lower in February (say), due for example to the virus-induced January-February collapse of a major trading partner (China). $\mathrm{ADS}=-14.5$.

March 26 (GDP Q4 release 3). Irrelevant. ADS=-14.5.

March 27 (February personal income, January real manufacturing and trade sales). Irrelevant. $\mathrm{ADS}=-14.3$.

April 2 (Initial jobless claims). IJC doubles off-the-charts, and ADS similarly doubles (downward) to -31. The Kalman smoother now has ADS beginning its decline in early January, again presumably an artifact of the serial correlation in IJC interacting with the Kalman smoother. Or, again, perhaps it's real. ADS=-31.0. 
April 3 (March payroll employment). PE drops but ADS rises. ADS evidently views the PE drop as good news, because it's not such a big drop compared to the off-the-charts $\mathrm{ADS}=-21.2$.

April 9 (Initial jobless claims). Another massive IJC increase, but ADS largely unchanged. $\mathrm{ADS}=-20.6$.

April 15 (March industrial production). IP plunges, but it's for the last month, and ADS actually continues its gradual upward mean reversion as initial claims improve. ADS=-17.1.

April 16 (Initial jobless claims). IJC drops some, and ADS improves. ADS=-11.1.

April 23 (Initial jobless claims). IJC and ADS again improve. ADS=-7.2.

April 29 (Q3 GDP, first release). $-4.8 \%$ annualized. 2008Q4 was worse $(-7.5 \%)$ but the 2020Q1 number was driven only by (part of) March. Had January, February, and early March 2020 been as bad as late March, 2020Q1 GDP growth would have been much worse. ADS is essentially unchanged. In the absence of the GDP news, ADS would presumably have risen, but the bad GDP news provided an offset. $\mathrm{ADS}=-6.9$.

April 30 (Initial jobless claims; March real personal income less transfer payments; February real manufacturing and trade sales). February RMTS is irrelevant. IJC continues slowly improving. PILTP for the previous month down sharply. The news is all bad, yet not so bad as it was, and ADS improves, now it approximately equals its worst value during the Great Recession. $\mathrm{ADS}=-3.9$.

May 7 (Initial jobless claims). IJC again improving. The IJC numbers continue to be bad, but they are getting less bad, and ADS seems driven by that. By this time the path plot makes clear that new data are causing sizable revisions in entire paths. For example, the huge ADS trough was estimated to be approximately -32 in the $4 / 2$ vintage, but it was progressively moved upward in subsequent vintages, and now in the $5 / 7$ vintage it is approximately $-12 . \mathrm{ADS}=-0.6$.

May 8 (Payroll employment). Plunges downward, and ADS plunges similarly to an all-time low. $\mathrm{ADS}=-36.2$.

May 14 (Initial jobless claims) IJC almost unchanged; ADS improves slightly to ADS=-32.6. 
May 15 (April industrial production). Plunges but ADS nevertheless ADS improves. ADS=26.9 .

May 21 (Initial jobless claims) IJC improves, and ADS improves to ADS=-22.9.

May 28 (Initial jobless claims; GDP Q1 second release) IJC improves slightly, Q1 GDP revised down slightly. ADS improves to $\mathrm{ADS}=-19.7$.

May 29 (Real manufacturing and trade sales, March; Real personal income less transfer payments, April) Both down sharply. ADS=-19.5.

June 4 (Initial jobless claims) IJC continues its ever-so-slow reversion to normalcy. ADS=16.8 .

June 5 (May payroll employment). PE increases sharply. Finally some surprising good news. ADS improves and goes positive. $\mathrm{ADS}=2.6$.

June 11 (Initial jobless claims). IJC improves slightly. ADS=3.6.

June 16 (May Industrial production). IP up, ADS unchanged. ADS=3.6.

June 18 (Initial jobless claims). IJC basically unchanged. ADS=3.1.

June 25 (Initial jobless claims). IJC basically unchanged. ADS=2.8.

June 16 (Real manufacturing and Trade Sales). MTS *****. ADS=*****. 


\section{References}

Aruoba, S.B. and F.X. Diebold (2010), "Real-Time Macroeconomic Monitoring: Real Activity, Inflation, and Interactions," American Economic Review, 100, 20-24.

Aruoba, S.B., F.X. Diebold, and C. Scotti (2009), "Real-time Measurement of Business Conditions," Journal of Business and Economic Statistics, 27, 417-427.

Bai, J. and S. Ng (2008), "Forecasting Economic Time Series Using Targeted Predictors," Journal of Econometrics, 146, 304-317.

BanBura, M., D. Giannone, and L. Reichlin (2011), "Nowcasting," In M. Clemens and D. Hendry, eds., Oxford Handbook of Economic Forecasting, 193-224.

Boivin, J. and S. Ng (2006), "Are More Data Always Better for Factor Analysis?" Journal of Econometrics, 132, 169-194.

Burns, A. and W.C. Mitchell (1946), Measuring Business Cycles, Columbia University Press for NBER.

Diebold, F.X. and G.D. Rudebusch (1991), "Forecasting Output with the Composite Leading Index: A Real-Time Analysis," Journal of the American Statistical Association, 86, 603610.

Doz, C., D. Giannone, and L. Reichlin (2012), "A Quasi-Maximum Likelihood Approach for Large, Approximate Dynamic Factor Models," Review of Economics and Statistics, 94, $1014-1024$.

Durbin, J. and S.J. Koopman (2001), Time Series Analysis by State Space Methods, Oxford: Oxford University Press.

Gunsilius, F. and S. Schennach (2019), "Independent Nonlinear Component Analysis," Manuscript, Departments of Economics, MIT and Brown Univeristy.

Harvey, A.C. (1991), Forecasting, Structural Time Series Models and the Kalman Filter, Cambridge: Cambridge University Press.

McCracken, M. and S. Ng (2016), "FRED-MD: A Monthly Database for Macroeconomic Research," Journal of Business and Economic Statistics, 36, 574-589. 
Sargent, T.J. and C.A. Sims (1977), "Business Cycle Modeling Without Pretending to Have too Much a Priori Theory," In C.A. Sims (ed.), New Methods in Business Cycle Research: Proceedings from a Conference, Federal Reserve Bank of Minneapolis, 45-109.

Stock, J. H. and M.W. Watson (1989), "New Indexes of Coincident and Leading Economic Indicators," In O. J. Blanchard and S. Fischer, eds., NBER Macroeconomics Annual, MIT Press, 351-393.

Stock, J. H. and M.W. Watson (2002), "Forecasting Using Principal Components from a Large Number of Predictors," Journal of the American Statistical Association, 97, 147162. 